\title{
Late Onset of Neuromyelitis Optica Spectrum Disorders
}

\author{
Yara Dadalti Fragoso (D) - Heloisa Helena Ruocco • Ronaldo Maciel Dias · Hideraldo Cabeça • \\ Ricardo Gonçalves · Nise A. de Carvalho Sousa • Caroline Vieira Spessotto • Carlos Bernardo Tauil • \\ Soniza Vieira Alves-Leon · Sidney Gomes • Marcus Vinicius M. Gonçalves • Suzana C. Nunes Machado • \\ Andrea Anacleto · Eber Castro Correa · Maria Lucia V. Pimentel · Gutemberg Augusto C. Santos
}

Received: April 25, 2019 / Published online: July 2, 2019

(C) The Author(s) 2019

\section{ABSTRACT}

Introduction: Neuromyelitis optica spectrum disorder (NMOSD) is an autoimmune demyelinating disease of the central nervous system. NMOSD starting after the age of 50 years is considered a "late onset" (LO-NMOSD) and seems to be particularly aggressive. The objective of this paper is to present a series of 37 Brazilian patients with LO-NMOSD.

Enhanced Digital Features To view enhanced digital features for this article go to https://doi.org/10.6084/ m9.figshare.8320433.

Y. D. Fragoso $(\varangle) \cdot$ A. Anacleto

Department of Neurology, Universidade

Metropolitana de Santos, Santos, SP, Brazil

e-mail: yara@bsnet.com.br

Y. D. Fragoso

MS and Headache Research, Santos, SP, Brazil

H. H. Ruocco

Department of Neurology, Pontificia Universidade Catolica de Campinas, Campinas, SP, Brazil

R. M. Dias - C. B. Tauil - E. C. Correa

Department of Neurology, Hospital de Base do

Distrito Federal, Brasilia, DF, Brazil

H. Cabeça

Department of Neurology, Hospital Ophir Loyola,

Belem, PA, Brazil

R. Gonçalves

Department of Neurology, Hospital Pompeia, Caxias

do Sul, RS, Brazil
Methods: Retrospective data collection from medical records of patients with LO-NMOSD seen at 14 Brazilian specialized units.

Results: The ratio of women to men in the sample was 4.3 to 1 . The patients were followed up for a median period of 4 years. Sex, age at disease onset, and ethnic background were not associated with the number of relapses or disability outcomes. Extensive longitudinal myelitis affected $86 \%$ of patients, while optic neuritis affected $70 \%$, and brainstem syndromes were present in only $16 \%$ of these patients. Six patients are currently using some type of support for walking or are wheelchair-bound. Three

\section{N. A. de Carvalho Sousa}

Department of Neurology, University Hospital

Getulio Vargas, Manaus, AM, Brazil

C. V. Spessotto

Department of Neurology, Santa Casa Misericordia de Aracatuba, Aracatuba, SP, Brazil

\section{S. V. Alves-Leon}

Department of Neurology, Universidade Federal do Rio de Janeiro, Rio de Janeiro, RJ, Brazil

\section{S. Gomes}

Department of Neurology, Hospital Beneficencia

Portuguesa de Sao Paulo and Hospital Paulistano, Sao Paulo, SP, Brazil

M. V. M. Gonçalves

Department of Neurology, Universidade da Regiao de Joinville, Joinville, SC, Brazil 
have died. Therapeutic options for NMOSD were particularly complicated for these elderly patients, since medications for controlling NMOSD are, in essence, immunosuppressive. Long-term use of corticosteroids can be an issue when the patients have high blood pressure, diabetes mellitus, or dyslipidemia (conditions often seen in elderly individuals).

Conclusion: This series of LO-NMOSD cases highlights the importance of prompt diagnosis and treatment for these patients.

Keywords: Elderly; Disability; Neurology; Neuromyelitis optica; Neuromyelitis optica spectrum disorders

\section{INTRODUCTION}

Neuromyelitis optica spectrum disorder (NMOSD) is a relapsing autoimmune neurological disease. For many years, it was a type of multiple sclerosis (MS), but it is now seen to be clearly different from MS [1, 2]. Antibodies against aquaporin-4 (AQP-4) are the hallmark of NMOSD, although not all patients present them. Presence of anti-AQP-4 autoantibodies relates to the unique immunopathology of the disease, but other autoantibodies like antimyelin glycoprotein (anti-MOG) may be involved in the disease [3]. These autoantibodies have helped define a "disease spectrum" beyond the classical definition of acute attacks of transverse myelitis and optic neuritis [2]. In 2015, the International Panel for NMO Diagnosis established the criteria currently used for diagnosing NMOSD [4].

NMOSD is often a severe condition with disabling outcomes. Demyelination and loss of

S. C. N. Machado

Department of Neurology, Hospital de Caridade, Florianopolis, SC, Brazil

M. L. V. Pimentel

Department of Neurology, Santa Casa de

Misericordia do Rio de Janeiro, Rio de Janeiro, RJ, Brazil

G. A. C. Santos

Department of Neurology, Universidade Estacio de Sa, Rio de Janeiro, RJ, Brazil astrocytes are the main pathological findings in the central nervous system [5]. The most common presentations of the disease are severe optic neuritis and extensive transverse myelitis [6]. Brainstem syndromes are less frequent but equally disabling [6]. Current treatment strategies include use of corticosteroids, immunoglobulins, and plasmapheresis for acute attacks, and general or humoral immunosuppression for prevention of attacks [5, 7].

NMOSD is more prevalent among women $[7,8]$, with typical onset between the third and fourth decades of life [8-10]. Starting the disease after the age of 50 years is infrequent and seems to be associated with worse outcomes. Patients with initial signs and symptoms occurring beyond age 50 are considered to present "lateonset NMOSD" (LO-NMOSD) [11].

There are a few papers reporting on anecdotal cases of LO-NMOSD [11-18]. Case series are rare in the literature, with reports on 45 patients with LO-NMOSD from Korea [11], 108 cases from France, Germany, Turkey, and the UK [19], and 30 patients from China [20]. The aim of the present study is to report on 37 Brazilian patients with LO-NMOSD and to discuss treatment limitations to this condition.

\section{METHODS}

Retrospective data were obtained from the medical charts of patients diagnosed with NMOSD in accordance with the 2015 criteria [4]. Only patients with at least 1 year of LONMOSD and records with complete information were included. The original study was approved by the Ethics Committee of Universidade Metropolitana de Santos, under the CAAE number 13994913.7.0000.5509. Additional ethical approval was obtained by each institution in accordance with its rules and regulations. Patients' consent was given at the time of enrollment in the Demyelinating Diseases Specialized Centers. Patient identity remains confidential and will not be disclosed in open or shared databases.

The patients self-reported their ethnic background. Disability was assessed using the Expanded Disability Severity Scale (EDSS) [21]. 
Anti-AQP-4 antibodies were tested using the immunofluorescence technique [22] and no patients had access to anti-MOG antibody testing. The results were presented in a descriptive manner and, whenever required, statistical analyses were carried out using GraphPad Prism. The Shapiro-Wilk test was used to assess normality, Student $t$ test was used to compare two means, while Chi-square test and Fisher exact test were used for independent criteria. Confidence intervals were established at 95\% and differences were reported as significant when $p<0.05$.

\section{RESULTS}

A summary of the results of 37 patients with LO-NMOSD is shown in Tables 1,2 , and 3 . Table 1 introduces patients' demographic data, Table 2 presents their clinical data, and Table 3 shows clinical manifestations of LO-NMOSD, anti-AQP-4 status, and number of patients relapsing despite therapy. The ratio of women to men in the sample was $4.3: 1$. Gender, age of disease onset, ethnic background, and positive antibodies for AQP-4 were not associated with the number of relapses or disability outcomes. The patients were followed up for a median period of 4 years. Extensive longitudinal myelitis was the most frequent manifestation of LONMOSD, affecting $86 \%$ of the patients. Optic neuritis affected $70 \%$ of the patients during the course of the disease, while brainstem

Table 1 Sex, ethnic background, and associated diseases of 37 patients with late-onset neuromyelitis optica

\begin{tabular}{lc}
\hline & Subjects \\
\hline Men & 7 \\
Women & 30 \\
White ancestry & 22 \\
Afro descendent & 15 \\
Hypertension & 12 \\
Diabetes mellitus & 4 \\
Sjogren's syndrome & 1 \\
\hline
\end{tabular}

Table 2 Clinical information on 37 patients with lateonset neuromyelitis optica

\begin{tabular}{|c|c|c|c|}
\hline & Median & Mean \pm SD & Range \\
\hline Age at onset (years) & 56 & $56.4 \pm 5.6$ & $50-75$ \\
\hline Present age (years) & 61 & $61.2 \pm 5.4$ & $53-78$ \\
\hline $\begin{array}{l}\text { Disease duration } \\
\text { (months) }\end{array}$ & 47 & $55.1 \pm 37.0$ & $12-148$ \\
\hline $\begin{array}{l}\text { Number of relapses } \\
\text { before diagnosis }\end{array}$ & 1 & $1.7 \pm 1.0$ & $1-3$ \\
\hline $\begin{array}{l}\text { Number of relapses } \\
\text { since diagnosis }\end{array}$ & 1 & $1.5 \pm 1.4$ & $0-4$ \\
\hline EDSS at diagnosis & 5.0 & $4.9 \pm 2.1$ & $1-8$ \\
\hline Present EDSS & 7.0 & $6.7 \pm 2.9^{a}$ & $1-10$ \\
\hline
\end{tabular}

Table 3 Response to treatment, serological anti-AQP-4, and clinical manifestations in 37 patients with late-onset neuromyelitis optica spectrum disorders

\begin{tabular}{lc}
\hline & $\begin{array}{l}\text { Number of } \\
\text { subjects }\end{array}$ \\
\hline Relapses on first treatment & 22 \\
Relapses on second treatment & 9 \\
Relapses on third treatment & 6 \\
Three or more relapses since & 10 \\
diagnosis & \\
Anti-AQP-4 positive & 24 \\
Anti-AQP-4 negative & 11 \\
Anti-AQP-4 not done & 2 \\
Myelitis & 32 \\
Optic neuritis & 26 \\
Brainstem syndrome & 6 \\
\hline$A Q P-4$ anti-aquaporin-4 antibodies &
\end{tabular}

syndromes were present in only $16 \%$ of them. Three patients died (EDSS $=10$ ) and six are currently using some type of support for walking or are wheelchair-bound (EDSS > 6.0). 
Sixty percent of the patients had relapses while using azathioprine (with or without corticosteroids) as their first-line therapy. Subsequently, either the azathioprine dose was increased or daily use of corticosteroids was added to these patients' therapy, but $41 \%$ of them still had relapses. Through use of rituximab, immunoglobulin, pulses of plasma exchange, or therapeutic associations, LONMOSD was brought under control in all but six patients, who continued to have relapses. The neurologists in charge of these patients reported that the best therapeutic option was high doses of azathioprine in association with daily oral corticosteroids (which controlled relapses in $70 \%$ of the patients). Rituximab controlled the most aggressive cases but, being an off-label therapy, access to this drug was very limited in the public health system.

\section{DISCUSSION}

Later age at onset and delay in diagnosing NMOSD have recently been described as independent factors for worse prognosis [8]. Differential diagnoses, age-related disease, and restriction on drug therapies pose particular challenges for these patients and their physicians. Chronic use of corticosteroids may be particularly difficult among individuals with diabetes, hypertension, gastrointestinal diseases, or osteoporosis. Pulses of methylprednisolone or dexamethasone, or plasma exchange, may be an option for elderly people, particularly those who do not have good tolerance for chronic use of corticosteroids [23]. Use of azathioprine has been correlated with higher risks of toxicity, infection, and malignancies [24]. Although high doses of azathioprine associated with daily oral prednisone was the firstline therapy for patients with LO-NMOSD in the present series, it is not easy to control the consequences of these drugs when administered chronically. On the other hand, the morbid consequences of underdosing or no treatment for these patients are well established. Despite the potential advantages of rituximab treatment, it cannot be used routinely for NMOSD in Brazil, since this is an off-label indication of the drug. The long-term risk-benefit relationship of rituximab is not well established for elderly individuals [25].

In comparing the present population of LONMOSD patients with data from a recent publication on Brazilian NMOSD patients of all ages [10], the more severe outcomes of older subjects are clear. In that series of 153 patients, the median age at NMOSD onset was 28 years. After a median follow-up of 7 years, EDSS was, on average, $5.4 \pm 2.5$. On the other hand, in the present population, LO-NMOSD led to significantly worse disability $(p=0.006)$ in just over half the time. This result is in line with what was reported by Seouk [11], Collongues [19], Mao [20], and Mealy [8]. Similar to the LONMOSD series of these authors, anti-AQP-4 antibodies were detected in $68 \%$ of the patients in the present study. As reported by those researchers, worse outcomes in LO-NMOSD cases were not associated with presence of antiAQP-4 antibodies in the present series, either.

The present study has limitations. It is based upon a population of only 37 subjects and has a short follow-up period. Anti-AQP-4 was essentially assessed by an immunofluorescence technique which is not the gold standard method. Not all subjects had anti-AQP-4 assessed and anti-MOG was not easily available at the time the population was assessed. Antibodies antiAQP-4 and anti-MOG are currently only available for private health care and are not covered or reimbursed by the public health system in Brazil.

Regarding therapeutic options, it is a challenge to receive a patient with LO-NMOSD in daily neuro-geriatric practice. The severity of the neurological disease and the age-related conditions the patient may present defy the physicians in charge of this individual. Patients with LO-NMOSD would have higher age-related risks of cardiovascular diseases, malignancies, and infections. They are also likely to make use of drugs to control chronic diseases, e.g., hypertension, diabetes, and dyslipidemia. To add corticosteroids, azathioprine, mycophenolate mofetil, and rituximab to the therapeutic scheme of these patients poses a neurotherapeutic challenge for which we have no guidelines yet. 


\section{CONCLUSION}

LO-NMOSD is a severe disabling condition. Neurologists must work closely with specialists in geriatric diseases in order to use drugs that can lead to the best therapeutic response, good tolerability, and minimal safety issues.

\section{ACKNOWLEDGEMENTS}

We thank the participants of the study.

Funding. No funding or sponsorship was received for this study or publication of this article.

Editorial Assistance. We are grateful to Carla Isobel Elliff, from G\&C Scientific Writing, for gracefully revising the final version of this paper. Editorial assistance was not funded.

Authorship. All named authors meet the International Committee of Medical Journal Editors (ICMJE) criteria for authorship for this article, take responsibility for the integrity of the work as a whole, and have given their approval for this version to be published.

Disclosures. Yara Dadalti Fragoso is a member of the journal's Editorial Board. Heloisa Helena Ruocco, Ronaldo Maciel Dias, Hideraldo Cabeça, Ricardo Gonçalves, Nise A. de Carvalho Sousa, Caroline Vieira Spessotto, Carlos Bernardo Tauil, Soniza Vieira Alves-Leon, Sidney Gomes, Marcus Vinicius M. Gonçalves, Suzana C. Nunes Machado, Andrea Anacleto, Eber Castro Correa, Maria Lucia V. Pimentel, and Gutemberg Augusto C. Santos have nothing to disclose.

Compliance with Ethics Guidelines. The original study was approved by the Ethics Committee of Universidade Metropolitana de Santos, under the CAAE number 13994913.7.0000.5509. Additional ethical approval was obtained by each institution in accordance with its rules and regulations. Patient consent was given at the time of enrollment in the Demyelinating Diseases Specialized Centers. Patient identity remains confidential and will not be disclosed in open or shared databases.

Open Access. This article is distributed under the terms of the Creative Commons Attribution-NonCommercial 4.0 International License (http://creativecommons.org/licenses/ by-nc/4.0/), which permits any noncommercial use, distribution, and reproduction in any medium, provided you give appropriate credit to the original author(s) and the source, provide a link to the Creative Commons license, and indicate if changes were made.

\section{REFERENCES}

1. Akaishi T, Nakashima I, Sato DK, Takahashi T, Fujihara K. Neuromyelitis optica spectrum disorders. Neuroimaging Clin N Am. 2017;27(2):251-65. https://doi.org/10.1016/j.nic.2016.12.010.

2. Weinshenker BG, Wingerchuk DM. Neuromyelitis spectrum disorders. Mayo Clin Proc. 2017;92(4):663-79. https://doi.org/10.1016/j. mayocp.2016.12.014.

3. Wu Y, Zhong L, Geng J. Neuromyelitis optica spectrum disorder: pathogenesis, treatment, and experimental models. Mult Scler Relat Disord. 2018;27:412-8. https://doi.org/10.1016/j.msard. 2018.12.002.

4. Wingerchuk DM, Banwell B, Bennett JL, et al. International consensus diagnostic criteria for neuromyelitis optica spectrum disorders. Neurology. 2015;85(2):177. https://doi.org/10.1212/wnl. 0000000000001729.

5. Jasiak-Zatonska M, Kalinowska-Lyszczarz A, Michalak S, Kozubski W. The immunology of neuromyelitis optica-current knowledge, clinical implications, controversies and future perspectives. Int J Mol Sci. 2016;17(3):273. https://doi.org/10. 3390/ijms17030273.

6. Han J, Yang MG, Zhu J, Jin T. Complexity and wide range of neuromyelitis optica spectrum disorders: more than typical manifestations. Neuropsychiatr Dis Treat. 2017;13:2653-60. https://doi.org/10. 2147/NDT.S147360.

7. Wingerchuk DM. Neuromyelitis optica spectrum disorders. Continuum (Minneap Minn). 
2010;16:105-21. https://doi.org/10.1212/01.CON. 0000389937.69413 .15 .

8. Mealy MA, Mossburg SE, Kim SH, et al. Long-term disability in neuromyelitis optica spectrum disorder with a history of myelitis is associated with age at onset, delay in diagnosis/preventive treatment, MRI lesion length and presence of symptomatic brain lesions. Mult Scler Relat Disord. 2018;28:64-8. https://doi.org/10.1016/j.msard.2018.12.011.

9. Carnero Contentti E, Soto de Castillo I, Daccach Marques V, et al. Application of the 2015 diagnostic criteria for neuromyelitis optica spectrum disorders in a cohort of Latin American patients. Mult Scler Relat Disord. 2018;20:109-14. https://doi.org/10. 1016/j.msard.2018.01.001.

10. Fragoso YD, Sousa NAC, Alves-Leon SV, et al. Clinical characteristics of 153 Brazilian patients with neuromyelitis optica spectrum disorder (NMOSD). Mult Scler Relat Disord. 2018;27:392-6. https://doi.org/10.1016/j.msard.2018.11.031.

11. Seok JM, Cho HJ, Ahn SW, et al. Clinical characteristics of late-onset neuromyelitis optica spectrum disorder: a multicenter retrospective study in Korea. Mult Scler. 2017;23(13):1748-56. https://doi.org/ $10.1177 / 1352458516685416$.

12. Krumbholz M, Hofstadt-van Oy U, Angstwurm K, et al. Very late-onset neuromyelitis optica spectrum disorder beyond the age of 75. J Neurol. 2015;262(5) :1379-84. https://doi.org/10.1007/s00415-015-77668.

13. Suchdev K, Razmjou S, Venkatachalam P, Khan OA, Mohamed W, Ibrahim MS. Late onset neuromyelitis optica mimicking an acute stroke in an elderly patient. J Neuroimmunol. 2017;309:1-3. https:// doi.org/10.1016/j.jneuroim.2017.04.006.

14. Souza CS, Brooks JB, Oliveira CL, Fragoso YD. Neuromyelitis optica with very late onset. Arq Neuropsiquiatr. 2013;71(8):556-7. https://doi.org/ 10.1590/0004-282X20130077.

15. Otani T, Irioka T, Takahashi YK, et al. Two cases of late-onset neuromyelitis optica spectrum disorder initially presenting with isolated cerebral white matter lesions. e-Neurol Sci. 2018;13:35-7. https:// doi.org/10.1016/j.ensci.2018.11.008.
16. Campbell A, Ogundipe OA. Neuromyelitis optica spectrum disorder presenting in an octogenarian. BMJ Case Rep. 2018. https://doi.org/10.1136/bcr2018-225601.

17. Amorim TA, Rocha-Filho PA. Neuromyelitis optica of very late onset: one more case. Arq Neuropsiquiatr. 2014;72(2):173. https://doi.org/10.1590/ 0004-282X20130211.

18. Lefaucheur R, Bourre B, Ahtoy P, et al. Neuromyelitis optica with very late onset. J Am Geriatr Soc. 2011;59(6):1138-40. https://doi.org/10.1111/j. 1532-5415.2011.03435.x.

19. Collongues N, Marignier R, Jacob A, et al. Characterization of neuromyelitis optica and neuromyelitis optica spectrum disorder patients with a late onset. Mult Scler. 2014;20(8):1086-94. https://doi. org/10.1177/1352458513515085.

20. Mao Z, Yin J, Zhong X, et al. Late-onset neuromyelitis optica spectrum disorder in AQP4seropositive patients in a Chinese population. BMC Neurol. 2015;15:160. https://doi.org/10.1186/ s12883-015-0417-y.

21. Kurtzke JF. Rating neurologic impairment in multiple sclerosis: an expanded disability status scale (EDSS). Neurology (Cleveland). 1983;33:1444-52.

22. Lennon VA, Wingerchuk DM, Kryzer TJ, et al. A serum autoantibody marker of neuromyelitis optica: distinction from multiple sclerosis. Lancet. 2004;364(9451):2106-12.

23. Hollen C, Suhaib O, Farrow A, Sidorov E. Elderly-onset neuromyelitis optica spectrum disorder with pre-existing prednisone allergy. Case Rep Neurol. 2018;10(1):25-8. https://doi.org/10.1159/000485120.

24. Montero N, Pérez-Sáez MJ, Pascual J, et al. Immunosuppression in the elderly renal allograft recipient: a systematic review. Transpl Rev (Orlando). 2016;30(3):144-53. https://doi.org/10.1016/j.trre. 2016.05.001.

25. Sailler L. Rituximab off label use for difficult-to-treat auto-immune diseases: reappraisal of benefits and risks. Clin Rev Allergy Immunol. 2008;34(1):103-10. https://doi.org/10.1007/s12016-007-8020-7. 